\title{
Avaliação de métodos de coleta de fezes para determinação da digestibilidade protéica em rã-touro (Rana catesbeiana)
}

\author{
Evaluation methods of feces collection for determination of protein digestibility \\ in bullfrog (Rana catesbeiana)
}

\author{
José Luiz Pedreira Mouriño ${ }^{1}$ Marta Verardino De Stéfani ${ }^{2}$
}

\section{RESUMO}

O presente trabalho teve como objetivo avaliar diferentes metodologias de coleta de fezes para determinação da digestibilidade protéica de alimentos para a rã-touro (Rana catesbeiana). As metodologias estudadas foram o método de coleta total das fezes; o método de coleta parcial das fezes usando indicador; o método de dissecação intestinal e o método por decantação de fezes com indicador, utilizando aquários para ensaios de nutrição com peixes. Os resultados dos $C D A_{P B}$ da ração obtidos para avaliação dos métodos de coleta foram: $62,1 \%, 65,0 \%, 61,3 \%$ e 70,3\%, respectivamente. Todos os métodos de coleta de fezes são adequados para a realização de ensaios de digestibilidade com rãs.

Palavras-chave: digestibilidade, rã-touro, Rana catesbeiana, métodos de coleta de fezes.

\section{ABSTRACT}

The present work had as objective to evaluate different methodologies of feces collection in the determination of the protein digestibility of food feeds for the bullfrog (Rana catesbeiana). The studied methodologies were: total collection of excrements, partial collection of excrements using indicator, intestinal dissection, and excrement decantation with pointer using aquariums for assays of nutrition with fish. The results for $C D A_{P B}$ obtained in this assay were: $62.1 \%, 65.0 \%, 61.3 \%$ and $70.3 \%$ respectively. All the methods of excrement collection can be executed for determination of protein digestibility in bullfrog.

Key words: digestibility, bullfrog, Rana catesbeiana, feces collection.

\section{INTRODUÇÃO}

No cultivo de rãs, como no de qualquer organismo aquático, a alimentação adequada é um fator importante para o desenvolvimento da espécie, representando, no caso de rãs, 57,1\% do custo total da criação (LIMA\& AGOSTINHO, 1988).

A exemplo de outras espécies animais, o conhecimento da digestibilidade dos ingredientes é indispensável para compor uma dieta balanceada, econômica e que atenda às exigências nutricionais das rãs. Entretanto, são as poucas informações relacionadas à nutrição destes animais são de experimentos com diferentes níveis. Nos trabalhos encontrados na literatura, observamos a utilização de valores quantitativos de energia bruta e de proteína bruta dos alimentos, ou mesmo a utilização de energia metabolizável (MONTEIRO et al., 1988; BARBALHO, 1991; MAZZONI et al., 1992; WIRZ et al., 1992 STEFANI, 1995).

Existem várias metodologias para coleta de fezes em estudos de nutrição com peixes. De acordo com SALLUM (2000), o seu desenvolvimento visa, principalmente, a contornar situações tais como o estresse dos animais pelo manuseio nos métodos de pressão abdominal, sucção anal, contenção em câmara metabólica ou alimentação forçada, o sacrifício dos animais do método de dissecação intestinal e a lixiviação de nutrientes e de energia, principalmente das fezes. Em um estudo realizado por ABIMORAD (2001), foram avaliados quatro métodos de coleta de fezes (dissecação, extrusão, sistema de Ghelph e sistema de Ghelph modificado), e o tempo mais eficiente para coleta de fezes nos sistemas de Guelph, analisando o coeficiente de digestibilidade da proteína bruta de uma

${ }^{1}$ Laboratório de Camarões Marinhos (LCM), Universidade Federal de Santa Catarina (UFSC), Beco dos Coroas, fundos, Barra da Lagoa, 88062-601, Florianópolis, SC, Brasil. E-mail: mourino@lcm.ufsc.br.

${ }^{2}$ Centro de Aqüicultura, Universidade Estadual Paulista (UNESP), Endereço: Via de Acesso Prof. Paulo Donato Castellane, s/n , 14884-900, Jaboticabal, SP, Brasil. E-mail: martavs@fcav.unesp.br. 
dieta para o pacu (Piaractus mesopotamicus). O autor relatou que todos os métodos estudados podem ser adotados com segurança para a espécie estudada, desde que sejam rigorosamente aplicados, e o intervalo de tempo entre as coletas de fezes em estudos de digestibilidade, por intermédio dos sistemas de Guelph, não deve ultrapassar 30 minutos. Como as informações obtidas com uma espécie não devem ser generalizadas exatamente para outras, devido a fatores específicos como comportamento e consistência das fezes, novos estudos deveriam ser realizados e podem ser tão importantes a ponto de impedir a utilização de determinados métodos.

CASTRO (1996) propôs um método de coleta total de fezes para estudo da digestibilidade dos alimentos para rãs e determinou os valores de energia metabolizável de alguns alimentos utilizados em rações de rãs. CASTRO et al. (1998) e BRAGA et al. (1998) aprimoraram a sua metodologia de coleta total de fezes e também avaliaram a energia metabolizável de alguns alimentos pelo mesmo método.

Considerando-se a importância de conhecer os valores nutritivos dos alimentos utilizados em dietas de rã-touro em engorda, e visto que, neste tipo de estudo, podem ocorrer problemas de lixiviação de nutrientes na água e contaminação por tecidos e/ou substâncias do próprio animal, mascarando assim os valores obtidos, torna-se necessário avaliar e comparar diferentes metodologias utilizadas na determinação dos valores de digestibilidade dos alimentos.

Portanto, o presente trabalho teve como objetivo avaliar diferentes métodos de alimentação e de coleta de fezes para determinação da digestibilidade da fração protéica de uma dieta comercial para a rãtouro.

\section{MATERIAL E MÉTODOS}

O experimento foi realizado no setor de Ranicultura e Laboratório de Nutrição de Organismos Aquáticos do Centro de Aqüicultura da Universidade Estadual Paulista, Campus de Jaboticabal, no período de janeiro a fevereiro de 2003.

Para os ensaios, foram utilizadas 120 rãstouro com peso médio de $\pm 135 \mathrm{~g}$ obtidas no Ranário Experimental do Centro de Aqüicultura. Estes animais foram alojados nas unidades experimentais, onde ficaram em jejum por um período de 48 horas, para adaptação ao meio ambiente e esvaziamento do tubo digestivo, de acordo com a metodologia descrita por CASTRO(1996).

Foram avaliadas quatro metodologias para coleta de fezes, para posterior determinação da digestibilidade protéica: coleta total das fezes, coleta parcial de fezes com indicador, dissecação intestinal e coleta por decantação. Para isso, foi utilizada uma ração comercial para trutas, contendo aproximadamente 402\%PB (Tabela 1) em um delineamento inteiramente casualizado, com quatro tratamentos e quatro repetições. As médias foram comparadas pelo teste de Tukey e ANOVA.

Em todos as metodologias, o sistema de alimentação adotado foi a alimentação forçada, proposta por CASTRO (1996) e aperfeiçoada por BRAGA et al. (1998), utilizando uma quantidade equivalente a $5 \%$ do peso vivo das rãs. $\mathrm{O}$ alimento fornecido foi moído e umedecido com água, em uma proporção de $80 \%$ do peso, posteriormente foi colocado em uma seringa de $10 \mathrm{ml}$, com a extremidade anterior cortada, sendo introduzida na boca do animal. A alimentação forçada foi realizada em duas etapas, onde foi administrado cerca de $50 \%$ da quantidade total do alimento na primeira etapa e o restante do alimento após a deglutição da primeira parcela, com os animais imobilizados com um pano.

Para o método de coleta total de fezes, foram utilizadas quatro caixas de polipropileno de 46 x 30 e $9 \mathrm{~cm}$ de profundidade com outra caixa de igual tamanho colocada sobreposta, para permitir a circulação de ar dentro do sistema e fazer a contenção dos animais. As caixas continham aproximadamente $300 \mathrm{ml}$ de água (trocada a cada coleta), para possibilitar a hidratação e termo-regulação das rãs. Foram montadas com uma leve inclinação para garantir dois terços do fundo das caixas secos e a outra parte preenchida com água. Cada caixa abrigou seis rãs com peso médio de $135 \mathrm{~g}$.

Nesta metodologia, o sistema de alimentação adotado foi a alimentação forçada proposta por CASTRO (1996) e aperfeiçoada por BRAGA et al. (1998), utilizando uma quantidade equivalente a $5 \%$ do peso vivo das rãs. O alimento fornecido foi moído e

Tabela 1 - Valor de F, coeficiente de variação e médias dos coeficientes de digestibilidade aparente da proteína bruta $\left(\mathrm{CDA}_{\mathrm{PB}}\right)$ para os diferentes métodos de coleta de fezes.

\begin{tabular}{ll}
\hline Valor de F & $4,5^{*}$ \\
\hline Coeficiente de variação (\%) & 6,6 \\
Médias de CD $\mathrm{PB}_{\mathrm{PB}}(\%)$ para: & $\mathrm{CD}_{\mathrm{PB}}(\%)$ \\
Coleta Total de Fezes & $62,1 \mathrm{~b}$ \\
Coleta parcial com óxido de cromo & $65,0 \mathrm{ab}$ \\
Coleta por decantação & $70,3 \mathrm{a}$ \\
Dissecação & $61,3 \mathrm{~b}$ \\
TUKEY & 7,7 \\
\hline
\end{tabular}

* Significativo ao nível de 5\%.

Ciência Rural, v.36, n3, mai-jun, 2006. 
umedecido com água, em uma proporção de $80 \%$ do peso, posteriormente foi colocado em uma seringa de $10 \mathrm{ml}$, com a extremidade anterior cortada, sendo introduzida na boca do animal. A alimentação forçada foi realizada em duas etapas, com os animais imobilizados com um pano, onde foi administrada cerca de 50\% da quantidade total do alimento na primeira etapa e o restante do alimento após a deglutição da primeira parcela.

Após o fornecimento da ração, todas as excretas (fezes e urina), juntamente com a água, foram coletadas por um período de 48 horas, com intervalos de quatro horas, para não acumular grande quantidade de material no fundo das caixas, acondicionadas em sacos plásticos identificados e colocados em freezer até o final do experimento. Posteriormente, foram descongeladas e secadas em estufa com circulação de ar a $55^{\circ} \mathrm{C}$ para secagem até peso constante e posterior moagem do material para análise de proteína bruta, seguindo a metodologia descrita por SILVA(1992). Para a determinação do coeficiente de digestibilidade aparente da proteína bruta $\left(\mathrm{CDA}_{\mathrm{PB}}\right)$, foi utilizada a seguinte equação:

$\mathrm{CDA}_{\mathrm{PB}}=\frac{\text { PB ingerida }-\mathrm{PB} \text { excretada } \times 100}{\mathrm{~PB} \text { ingerida }}$

Para o método de coleta parcial de fezes com indicador, também foram utilizados quatro caixas de polipropileno, com seis rãs em cada caixa, e o sistema de alimentação forçada, descritos anteriormente. Neste ensaio, foi adicionado $0,5 \%$ de óxido de cromo na ração, como marcador inerte. As fezes foram coletadas por um período de 48 horas, com intervalos de quatro horas, sendo coletada parte das fezes que vinham dissolvidas na água, deixando o resto das excretas nas caixas. Em seguida o material foi acondicionado e processado, como descrito anteriormente. Foram realizadas análises de óxido de cromo nas fezes e na ração, pelo método de digestão com ácidos nítrico e perclórico, de acordo com a metodologia descrita por FURUKAWA \& TSUKAHARA (1966). Por meio de equação descrita por NOSE (1966), foi estimada a digestibilidade aparente da fração protéica $\left(\mathrm{CDA}_{\mathrm{PB}}\right)$.

\section{$\mathrm{CDA}_{\mathrm{PB}}=\underline{100-100(\% \text { indicador na dieta) } \mathrm{X}(\% \text { nutrientenas fezes })}$ (\% indicador nas fezes)x(\% do nutriente na dieta)}

No método de dissecação intestinal, foi utilizada a mesma ração com marcador inerte (ração + 0,5\% óxido de cromo), pela técnica da alimentação forçada. Os animais ficaram abrigados nas caixas de polipropileno descritas anteriormente, com seis rãs em cada caixa. Nesta metodologia, os animais foram sacrificados de oito em oito horas, e as fezes coletadas por dissecação diretamente no intestino grosso. Este intervalo foi proposto após a observação, em um préensaio, no qual, após seis horas da alimentação forçada, já havia fezes em algumas caixas. As fezes coletadas foram acondicionadas e processadas como descrito anteriormente. Foram efetuadas análises de óxido de cromo nas fezes e na ração (FURUKAWA \& TSUKAHARA, 1966) e a digestibilidade da fração protéica foi calculada de acordo com NOSE (1966).

O método de coleta de fezes com indicador utilizando aquários de coleta de fezes por decantação para peixes consistiu no uso de aquários cilíndricos de fibra de vidro com capacidade para 80L e fundo cônico, no qual foram colocadas seis rãs por aquário. A altura da água no aquário só alcançava a parte cônica, deixando apoio para os animais não se afogarem. A água foi trocada a cada coleta para não acumular material endógeno (urina) dos animais, e o escoamento era pelo fundo. As fezes que decantavam no aquário eram depositadas na extremidade inferior do mesmo em tubos de vidro até o momento da coleta, na qual foram utilizados registros de esfera para facilitar a coleta. Para determinação da digestibilidade aparente da proteína bruta da ração, foi adicionado 0,5\% de óxido de cromo como marcador inerte. Foi utilizada a técnica de alimentação forçada descrita anteriormente.

O período de coleta após a administração da ração foi de 48 horas sem interrupção, com intervalos de quatro horas para não acumular material no aquário. As fezes foram coletadas e processadas como descrito anteriormente, para determinação dos teores de proteína bruta e digestibilidade, de acordo com as metodologias descritas por FURUKAWA \& TSUKAHARA (1966) e NOSE (1966).

Para a avaliação dos métodos de coleta de fezes, foram utilizados os valores de digestibilidade da fração protéica observados para a dieta, obtidos com as fezes coletadas em cada um dos métodos.

Para avaliação do tempo de lixiviação da coleta de fezes, foi realizado um ensaio utilizando-se a metodologia de coleta de fezes por decantação, descrita anteriormente, no qual as fezes foram coletadas quando começaram a aparecer nos tubos, em intervalos de trinta minutos ou de quatro horas, durante 48 horas. Neste ensaio, para a análise estatística, foi considerado como tempo zero de coleta o dado obtido no intestino grosso pelo método de dissecação, utilizando um delineamento inteiramente casualizado, com três tratamentos e quatro repetições.

Ciência Rural, v.36, n.3, mai-jun, 2006. 


\section{RESULTADOS E DISCUSSÃO}

Os valores médios de $\mathrm{CDA}_{\mathrm{PB}}$ encontrados para a coleta total de fezes (62,09\%) e para a coleta parcial com óxido de cromo $(65,00 \%)$ não diferiram significativamente do método de coleta por dissecação (61,31\%).Os métodos de coleta de fezes apresentaram diferenças significativas $(\mathrm{P}<0,05)$, mostrando que as diferentes metodologias influenciaram os valores dos coeficientes de digestibilidade aparente da fração protéica $\left(\mathrm{CDA}_{\mathrm{PB}}\right)$ da dieta (Tabela 2).

O método de coleta de fezes por decantação em aquários apresentou o maior valor de $\mathrm{CDA}_{\mathrm{PB}}$ (70,33\%) (Tabela 1) em relação as outras metodologias. Isso provavelmente ocorreu porque, nesta metodologia, houve menor contaminação do material fecal, pois quando as fezes eram recolhidas, separava-se possíveis contaminantes como a pele, e a água era trocada a cada coleta para não acumular material endógeno. Além disso, quando comparado com os valores de $\mathrm{CDA}_{\mathrm{PB}}$ encontrados no método da dissecação, pode ter ocorrido também uma lixiviação dos nutrientes, visto que as fezes foram coletadas a cada quatro horas. Apesar disso, nesta metodologia, o valor de $\mathrm{CDA}_{\mathrm{PB}}$ não diferiu significativamente do método de coleta parcial com óxido de cromo, o qual foi realizada nas caixas de polipropileno. Entretanto, diferiu da média do valor de $\mathrm{CDA}_{\mathrm{PB}}$ obtida na metodologia de coleta total de fezes, foi significativamente menor que o da coleta por decantação, provavelmente pela quantidade de água que foi levada à estufa para secagem do material e pela presença de contaminações por tecidos e/ou substâncias do próprio animal, não servindo para cálculo de digestibilidade dos nutrientes devido às contaminações.

No método de dissecação intestinal, foi observada dificuldade em se obter a quantidade mínima de fezes para análises de óxido de cromo e proteína

Tabela 2 - Valores de F, coeficiente de variação e médias dos coeficientes de digestibilidade aparente da proteína bruta $\left(\mathrm{CDA}_{\mathrm{PB}}\right)$ nos diferentes intervalos de recolhimento de fezes para rã-touro.

\begin{tabular}{ll}
\hline Valor de $\mathrm{F}$ & $2,9^{*}$ \\
\hline Coeficiente de variação (\%) & 7,6 \\
Médias de $\mathrm{CD}_{\mathrm{PB}}(\%)$ para: & $\mathrm{CD}_{\mathrm{PB}}(\%)$ \\
Tempo 0 (método de dissecação) & $61,3 \mathrm{~b}$ \\
Intervalo de 30 minutos & $67,1 \mathrm{a}$ \\
Intervalo de 4 horas & $70,3 \mathrm{a}$ \\
TUKEY & 7,6 \\
\hline
\end{tabular}

* Significativo ao nível de 5\% bruta, devido à pequena quantidade de material encontrada nos segmentos do trato digestório e no trânsito intestinal. Os resultados obtidos com este tratamento podem ter sido subestimados devido à contaminação das fezes com a urina e a mucosa do intestino, visto que as fezes foram retiradas espremendo-se as partes do trato digestório. De acordo com AUSTRENG (1978), a pressão durante a dissecação pode provocar ocasionalmente injúrias nas vísceras e, desta forma, a adição de nitrogênio endógeno, como muco e células epiteliais, às fezes, diminuindo assim os valores da digestibilidade.

As médias dos $\mathrm{CDA}_{\mathrm{PB}}$ obtidas com os métodos de coleta total de fezes e coleta parcial com óxido de cromo não deferiram significativamente $(\mathrm{P}>0,05)$ e ambas também podem ter sido subestimadas devido à contaminação das fezes por muco, pele dos animais e até mesmo por partículas de alimentos regurgitados, como foi observado por RAMSAY et al. (2000). Os valores médios de $C D A_{\mathrm{PB}}$ encontrados para a coleta total de fezes $(62,09 \%)$ e coleta parcial com óxido de cromo $(65,00 \%)$ não diferiram significativamente do método de coleta por dissecação (61,31\%).

Os diferentes valores observados para o $\mathrm{CDA}_{\mathrm{PB}}$ podem ser explicados por vários motivos. O primeiro seria uma inevitável perda de proteína das fezes para a água no método de defecação na água, podendo ainda ocorrer lixiviação de pequena parte do óxido de cromo, aumentando assim o valor da digestibilidade. Outro fator é a contaminação fecal que pode ter ocorrido nos métodos que usaram as caixas de coleta, considerando-se que uma quantidade razoável de urina, pele e muco poderiam ter se juntado às fezes, mesmo havendo uma pequena separação, resultado evidenciado por ABIMORAD (2001).

SILVA et al. (1999) não encontraram diferenças significativas avaliando os métodos de decantação na água Guelph e o método de dissecação para a determinação da digestibilidade de alimentos para o tambaqui, discordando dos resultados obtidos no presente trabalho.

Corroborando os resultados do presente trabalho, SPYRIDAKIS et al. (1989) concluíram que o método de coleta de fezes com sistema de decantação era o mais apropriado para trabalhos com digestibilidade para peixes, pois não havia manipulação dos peixes, não provocando estresse, e as fezes eram coletadas automaticamente, à medida que eram evacuadas.

No ensaio para observar a ocorrência de perda de nutrientes por lixiviação, nos diferentes intervalos de tempo entre as coletas, através do método 
por decantação, as médias evidenciaram que não houve diferença significativa nos valores do $\mathrm{CDA}_{\mathrm{PB}}$ para fezes coletadas em intervalos de trinta minutos ou quatro horas (Tabela 2). Mesmo não havendo diferença significativa entre os intervalos de trinta minutos e quatro horas, foi possível observar que houve uma tendência de aumento no valor da digestibilidade com o aumento no intervalo de tempo de coleta, indicando a ocorrência de pequenas perdas de nutrientes por lixiviação. Comparando estes resultados com o método de dissecação, onde o tempo de lixiviação é zero, temse uma diferença significativa, sugerindo assim um intervalo de tempo de coleta inferior a trinta minutos para tentar diminuir ao máximo a perda de nutrientes e superestimar os valores de CDA ${ }_{\mathrm{PB}}$, resultado também encontrado por ABIMORAD (2001).

\section{CONCLUSÃO}

Todos os métodos de coleta de fezes são adequados para a realização de ensaios de digestibilidade com rãs. Devido aos resultados obtidos neste trabalho, estudos devem ser priorizados comparando os métodos de dissecação sem espremer o trato intestinal e de coleta de fezes por decantação, com circulação de água, com intervalos inferiores a trinta minutos.

\section{REFERÊNCIAS}

ABIMORAD, E.G.; CARNEIRO, D.J. Fecal collection methods and determination of crude protein and of gross energy digestibility coefficients of feedstuffs for pacu, Piaractus mesopotamicus (Holmberg, 1887). Revista Brasileira de Zootecnia, v.33, n.5, p.1101-1109, 2004.

AUSTRENG, E. Digestibility determination in fish using chromic oxide marking and analysis of from different segments of the gastrointestinal tract. Aquaculture, Amsterdam, v.13, p.265-272, 1978.

BARBALHO, O.J.M. Exigência de proteína bruta de rãtouro (Rana catesbeiana, Shaw 1802) na fase de terminação. 1991. 55f. Dissertação (Mestrado em Zootecnia) - Curso de Pós-graduação em Zootecnia, Universidade Federal de Viçosa.

BRAGA, L.G.T. et al. Valor nutricional de alguns alimentos para rã-touro (Rana catesbeiana, Shaw 1802) na fase de recria. Revista Brasileira de Zootecnia,Viçosa, v.27, p.203-209, 1998.

CASTRO, J.C. Estrutura funcional do tubo digestivo e adaptação de uma metodologia para determinar os valores de energia metabolizável de alimentos para rã touro (Rana catesbeiana Shaw, 1802). 1996. 120f. Tese (Doutorado em Zootecnia) - Curso de Pós-graduação em Zootecnia, Universidade Federal de Viçosa.

CASTRO, J.C. Energia metabolizável de alguns alimentos usados em rações de rãs. Revista Brasileira de Zooctecnia, Viçosa, v.27, n.6, p.1051-1056, 1998.

FURUKAWA, A.A.; TSUKAHARA, H. On the acid digestion for the determination of chrornic oxide as index substance in the study of digestibility of fish feed. Bulletin of the Japanese Society of Fisheries, Minato, v.32, n.6, p.502506, 1966.

LIMA, S.L.; AGOSTINHO,C.A. A criação de rãs. Rio de Janeiro: Globo, 1988. 187p.

MAZZONI, R. et al. Estudio del porcentaje de proteína y la energía en el alimento peleteado para engorde de rana toro (Rana catesbeiana, Shaw 1802). In: ENCONTRO NACIONAL DE RANICUlTURA, 7., 1992, Rio de Janeiro, RJ. Anais... Rio de Janeiro: Associação dos Ranicultores do Estado do Rio de Janeiro, 1992. p.185-190.

NOSE, T. Recent advances in the study of fish digestion in Japan. In: SIMPOSIUM ON FINFISH NUTRITION AND FISH FEED TECHNOLOGY, 1966, Belgrade. Proceedings... Belgrade: EIFAC/FAO, 1966. 15p.

RAMSAY, J.M. et al. Effects of fecal collection methods on estimation of digestibility of protein feedstuffs by "winter flounder”. North American Journal of Aquaculture, Truro, v.66, p.168-173, 2000.

SALLUM, W.B. Óxido crômico III como indicador externo em ensaios metabólicos para o matrinchã (Bricon cephalus, Gunther 1869) (Teleostei, Characidae). 2000. 116f. Tese (Doutorado em Zootecnia) - Universidade Federal de Lavras.

SILVA, J.A.M. da et al. Digestibility of seeds consumed by tambaqui (Colossoma macropomum Cuvier, 1818): an experimental approach. In: VAL, A.L.; ALMEIDA VAL, V.M.F. (ed). Biology of tropical fishes. Manaus: INPA, 1999. Cap.11, p.137-148.

SILVA, D.J. Análise de alimentos (métodos químicos e biológicos). Viçosa: UFV, 1992. 165p.

SPYRIDAKIS, P. et al. Studies on nutrient digestibility in European sea bass (Dicentrarchus Iabrax) I. Methodological aspects concerning faeces collection. Aquaculture, Amsterdam, v.77, p.61-70, 1989.

WIRZ, R.R. et al. Ganho de peso de rã-touro (Rana catesbeiana , Shaw 1802) criada em gaiolas, com rações de diferentes níveis protéicos, consorciada com larvas de díptera (Musca doméstica). Boletim do Instituto de Pesca, São Paulo, v.19 (único), p.83-88, 1992. 